\title{
NEW SHARP BOUNDS FOR IDENTRIC MEAN IN TERMS OF LOGARITHMIC MEAN AND ARITHMETIC MEAN
}

\author{
ZHEN-HANG YANG
}

Abstract. Let $x, y>0$ with $x \neq y$. We give new sharp bound for identric mean $I=e^{-1}\left(x^{x} / y^{y}\right)^{1 /(x-y)}$ in terms of logarithmic mean $L=(x-y) /(\ln x-\ln y)$ and arithmetic mean $A=(x+y) / 2$ :

$$
\left(\frac{1}{2} L^{p_{0}}+\frac{1}{2} A^{p_{0}}\right)^{1 / p_{0}}<I<\left(\frac{1}{2} L^{\tilde{p}_{0}}+\frac{1}{2} A^{\tilde{p}_{0}}\right)^{1 / \tilde{p}_{0}},
$$

where $p_{0}=8 / 5$ and $\tilde{p}_{0}=(\ln 2) /(1-\ln 2)$ are the best possible constants.

Mathematics subject classification (2010): 26D07, 26E60.

Keywords and phrases: Logarithmic mean, identric mean, arithmetic mean, inequality.

\section{REFERENCES}

[1] G. D. Anderson, M. K. Vamanamurthy and M. Vuorinen, Conformal Invariants, Inequalities, and Quasiconformal Maps, New York 1997.

[2] H. AlzER, Aufgabe 987, Elem. Math., 43, 93 (1988), (German).

[3] H. Alzer And S.-L. QIU, Inequalities for means in two variables, Arch. Math. (Basel), 80 (2003), 201-215.

[4] M. BIERNACKI AND J. KRZYZ, On the monotonity of certain functionals in the theory of analytic functions, Annales Universitatis Mariae Curie-Sklodowska, 9 (1995), 135-147.

[5] P. S. Bullen, D. S. Mitrinović And P. M. VAsić, Means and Their Inequalities, Dordrecht 1988.

[6] O. KoubA, New bounds for the identric mean of two arguments, J. Inequal. Pure Appl. Math., 9, 3 (2008), Art. 71, 6 pages.

[7] E. NEUMAN AND J. SÁndoR, On certain means of two arguments and their extensions, Int. J. Math. Math. Sci., 2003, 16(2003), 981-993.

[8] E. Neuman And J. SÁndor, Inequalities involving Stolarsky and Gini means, Math. Pannon., 14, 1 (2003), 29-44.

[9] A. O. Pittinger, Inequalities between arithmetic and logarithmic means, Univ. Beograd Publ. Elektr. Fak. Ser. Mat. Fiz, 680 (1980), 15-18.

[10] Y.-F. QIU, M.-K. WANG, Y.-M. CHU AND G.-D. WANG, Two sharp inequalities for Lehmer mean, identric mean and logarithmic mean, J. Math. Inequal., 5, 3 (2011), 301-306.

[11] J. SÁndor, On the identric and logarithmic means, Aequat. Math., 40 (1990), 261-270 .

[12] J. SÁNDOR, A note on some inequalities for means, Arch. Math., 56 (1991), 471-473.

[13] J. SÁndor, Two inequalities for means, Int. J. Math. Math. Sci., 18, 3 (1995), 621-623. MR 96b:26030. Zbl 827.26016.

[14] J. SÁndoR, On certain inequalities for means III, Arch. Math., 76 (2001), 34-40.

[15] J. SÁNDOR AND T. TRIF, Some new inequalities for means of two arguments, Internat. J. Math. Math. Sci., 25 (2001), 525-532.

[16] K. B. Stolarsky, Generalizations of the logarithmic mean, Math. Mag., 48 (1975), 87-92.

[17] K. B. Stolarsky, The power and generalized logarithmic means, Amer. Math. Monthly, 87 (1980), 545-548.

[18] T. TRIF, Note on certain inequalities for means in two variables, J. Inequal. Pure Appl. Math., 6, 2(2005), Art. 43; available online at http://jipam.vu.edu.au/article.php?sid=512. 
[19] M. K. Vamanamurthy And M. Vuorinen, Inequalities for means, J. Math. Anal. Appl., 183 (1994), 155-166.

[20] ZH.-H. YANG, Exponential mean and logarithmic mean, Mathematics in Practice and Theory, 1987, 4 (1987), 76-78, (Chinese)

[21] ZH.-H. YANG, On the homogeneous functions with two parameters and its monotonicity, J. Inequal. Pure Appl. Math., 6, 4 (2005), Art. 101; available online at http://jipam.vu.edu.au/images/155_05_JIPAM/155_05.pdf.

[22] ZH.-H. YANG, On the log-convexity of two-parameter homogeneous functions, Math. Inequal. Appl., 10, 3 (2007), 499-516.

[23] ZH.-H. YANG, On the monotonicity and log-convexity of a four-parameter homogeneous mean, J. Inequal. Appl., 2008 (2008), Art. ID 149286, 12 pages, doi:10.1155/2008/149286; available online at http://www.hindawi.com/GetArticle.aspx?doi=10.1155/2008/149286.

[24] ZH.-H. YANG, Log-convexity of ratio of the two-parameter symmetric homogeneous functions and an application, J. Inequal. Spec. Func., 1, 1(2010), 16-29; available online athttp://www.ilirias.com.

[25] ZH.-H. YANG, The log-convexity of another class of one-parameter means and its applications, Bull. Korean Math. Soc., 49, 1(2012), 33-47; available online at http://dx.doi.org/10.4134/BKMS. 2012.49.1.033.

[26] L. ZHU, New inequalities for means in two variables, Math. Inequal. Appl., 11, 2 (2008), 229-235. 